[0212-7199 (2005) 22: 3; pp 108-113] ANALES DE MEDICINA INTERN Copyright (C) 2005 ARAN EDICIONES, S.L.

AN. MED. InTERnA (Madrid) Vol. 22, N. ${ }^{\circ}$ 3, pp. 108-113, 2005

\title{
Pronóstico de las bacteriemias adquiridas en la comunidad ingresadas en un Servicio de Medicina Interna
}

\author{
E. LIZARRALDE PALACIOS, A. GUTIÉRREZ MACÍAS, P. MARTÍNEZ \\ ODRIOZOLA, J. IBARMIA LAHUERTA, F. M. DE LA VILLA
}

Servicio de Medicina Interna. Hospital de Basurto. Bilbao

OUTCOME OF COMMUNITY-ACQUIRED BACTEREMIA ADMITTED TO AN INTERNAL MEDICINE DEPARTMENT

\section{RESUMEN}

Objetivo: Estudiar la mortalidad y los factores asociados a la misma en las bacteriemias adquiridas en la comunidad que ingresan en el servicio de Medicina Interna de un hospital terciario.

Pacientes y métodos: Estudio prospectivo de las bacteriemias ingresadas durante 1 año (mayo 1999-abril 2000). Se han recogido datos demográficos, patología previa, situación funcional, foco infeccioso, complicaciones, constantes vitales, valores de laboratorio, puntuaciones del APACHE II y SOFA, resultados de los hemocultivos, tratamiento y supervivencia a los 28 días. En primer lugar se ha realizado un análisis bivariante con la prueba de la Chi-cuadrado, la t de Student y la prueba no paramétrica de Mann-Whitney, según correspondiera. Las variables significativas se han introducido en un modelo de regresión logística múltiple de exclusión escalonada paso a paso, utilizando la mortalidad como variable dependiente.

Resultados: Se han observado 115 casos de bacteriemia en 114 pacientes. El foco urinario supuso el $57,4 \%$ de los casos y el microorganismo aislado con mayor frecuencia fue Escherichia coli $(54,4 \%$ de los aislamientos). La mortalidad a los 28 días fue del 15,3\%. Los factores asociados de forma independiente a la misma fueron el shock séptico (OR 10,4), el foco de bacteriemia diferente del urinario (OR 9,3), la puntuación en el APACHE II mayor o igual a $20($ OR 5,5) y la existencia de un estado funcional dependiente previo al episodio (OR 4,8).

Conclusiones: Los factores de riesgo de mortalidad fueron el shock séptico, el foco no urinario, la puntuación del APACHE II y el estado funcional previo.

PALABRAS CLAVE: Bacteriemia.

\section{ABSTRACT}

Objective: To analyze mortality and associated factors in commu nity-acquired bacteremia admitted to an Internal Medicine Department.

Patient and methods: Prospective study of bacteremia admitted in 1 year (May 1999-April 2000). We have collected demographic data, previous comorbid conditions, functional status, source of infection, complications, vital signs, laboratory values, APACHE II and SOFA scores, blood cultures, therapy and 28-day mortality. In bivariate analysis, we have used Chi-square, Student-t test and Mann-Whitney $U$ as needed. Significant variables have been introduced in a stepwise backward logistic regression model with mortality as the dependent variable.

Results: We have observed 115 episodes of bacteremia in 114 patients. The source of bacteremia was urinary tract in $57.4 \%$ episodes and the most common isolate was Escherichia coli (54.4\%). 28-day mortality was $15.3 \%$. Factors independently associated with mortality were septic shock (OR 10.4), non-urinary source of bacteremia (OR 9.3), APACHE II score higher than 20 (OR 5,5), and previous dependent functional status (OR 4.8).

Conclusions: Mortality risk factors were septic shock, non-urinary source of bacteremia, APACHE II score and dependent functional status.

Lizarralde Palacios E, Gutiérrez Macías A, Martínez Odriozola P, Ibarmia Lahuerta J, de la Villa FM. Pronóstico de las bacteriemias adquiridas en la comunidad ingresadas en un Servicio de Medicina Interna. An Med Interna (Madrid) 2005; 22: 108-113.

\section{INTRODUCCIÓN}

Las enfermedades infecciosas y en particular las bacteriemias, han experimentado en los últimos años un incremento notable en frecuencia y morbimortalidad. La incidencia de bacteriemia oscila entre 4,5 y 36 por mil ingresos, dependiendo del ámbito de realización del estudio, de la población analizada y del lugar de adquisición de la bacteriemia (1-3). Además, en las últimas décadas se ha observado un cambio en su espectro clínico y epidemiológico, asociado a la mayor utilización de procedimientos diagnósticos y terapéuticos invasivos, y al aumento de la prevalencia de

Trabajo aceptado: 8 de noviembre de 2004

Correspondencia: Eva Lizarralde Palacios. Servicio de Medicina Interna. Hospital de Basurto. Avda. de Montevideo, 18.48013 Bilbao. e-mail: alguma@teleline.es 
procesos patológicos que condicionan una alteración de la inmunidad $(4,5)$. La bacteriemia, independientemente de su etiología, es un proceso grave, que causa una mortalidad en torno a un $15-25 \%$ (6); por otra parte, produce un aumento de la estancia media hospitalaria y requiere una mayor utilización de recursos, contribuyendo a incrementar los costes sanitarios de forma significativa. El objetivo de este trabajo es analizar el pronóstico y los factores asociados a la mortalidad en las bacteriemias adquiridas en la comunidad, que requieren ingreso en un servicio de Medicina Interna de un hospital terciario.

\section{PACIENTES Y MÉTODOS}

Hemos realizado un estudio prospectivo, incluyendo de forma consecutiva a todos los enfermos ingresados en el Servicio de Medicina Interna desde el 1 de mayo de 1999 hasta el 30 de abril del 2000 con el diagnóstico de bacteriemia adquirida en la comunidad. Se han excluido las bacteriemias de adquisición nosocomial, definidas como las presentes en pacientes con ingresos hospitalarios recientes (en los 7 días previos) y las que producían síntomas no relacionados con el motivo de ingreso y que aparecían al menos 72 horas después del mismo.

La información se obtuvo mediante la revisión de la historia clínica y la entrevista directa, tanto a los pacientes como a sus familiares. En todos los casos incluidos se ha cumplimentado un protocolo en el que se recogían datos demográficos (edad y sexo); existencia de patología asociada previa al episodio, medida con el índice de comorbilidad de Charlson (7) y su pronóstico, definido como no fatal, últimamente fatal y rápidamente fatal según los criterios de McCabe y Jackson (8). Se consideró que un paciente padecía una enfermedad rápidamente fatal cuando la expectativa de supervivencia era inferior a 2 meses, últimamente fatal cuando la probabilidad de muerte en los próximos 5 años era alta, y no fatal cuando no existía patología de base o ésta, razonablemente, no conduciría a la muerte del paciente en los siguientes 5 años. Por otra parte, se determinó la situación funcional previa al episodio según la escala de Plutchik; se definió una situación funcional como dependiente si la puntuación en la escala era $\geq 8$ puntos (9). Se recogió la presencia de factores favorecedores del desarrollo de infección o bacteriemia, prestando especial atención a los antecedentes de manipulaciones urológicas o sondaje uretral, tratamiento inmunosupresor, existencia de diabetes, cirrosis, neoplasias o infección por VIH. Se hicieron constar los datos, tanto clínicos como de las exploraciones complementarias, que apoyaran la existencia de un posible foco infeccioso. Se recogió además la existencia de complicaciones, tales como disminución del nivel de conciencia, oliguria, hipotensión o shock e insuficiencia respiratoria. Además, se registraron las constantes vitales y los valores de laboratorio más próximos en el tiempo a la extracción del hemocultivo. El nivel de conciencia se determinó con la escala de coma de Glasgow (10). Se han calculado las puntuaciones de las escalas de gravedad APACHE II (11) y SOFA (12). Además se recogieron los resultados de los hemocultivos y de otros cultivos, el tratamiento recibido, la evolución durante el ingreso y la supervivencia a los 28 días del inicio del episodio. El seguimiento de los pacientes se realizó con el soporte informático del hospital, comprobando la existencia de episodios posteriores, citas en consultas externas, en la Unidad de Extrac- ciones y en Radiodiagnóstico. En los pacientes que no fueron localizados de esta manera se realizaron al menos tres llamadas telefónicas, en días distintos, al número de teléfono que constaba en los datos administrativos de la historia clínica.

En todos los casos se obtuvieron tres pares de hemocultivos seriados, extrayendo mediante técnica estéril $10 \mathrm{ml}$ de sangre venosa en cada ocasión, que se han inoculado en medios de cultivo aerobio y anaerobio. Los viales de hemocultivos se procesaron mediante el sistema Bactec 9240 (Becton-Dickinson). Los microorganismos aislados fueron identificados mediante las técnicas microbiológicas convencionales. Se definió bacteriemia como el aislamiento de microorganismos de patogenicidad reconocida en uno o más hemocultivos de un paciente con un contexto clínico compatible. El diagnóstico síndrómico de los pacientes se realizó ante una combinación de criterios clínicos, microbiológicos y de técnicas de imagen establecidos previamente (13).

\section{ESTUDIO ESTADÍSTICO}

En el estudio estadístico descriptivo, las variables continuas se expresan con la media y desviación estándar, y las cualitativas con el porcentaje. En el análisis de la mortalidad se ha considerado de forma conjunta la atribuible a la bacteriemia y la asociada a otras causas. Para evaluar los factores asociados se ha realizado en primer lugar un análisis bivariante considerando como variable dependiente la mortalidad a los 28 días. La comparación entre variables cualitativas se ha realizado con la prueba de la Chi-cuadrado y el test exacto de Fischer. Para realizar comparaciones entre medias de las variables cuantitativas, inicialmente se ha realizado una prueba de Kolmogorov-Smirnoff para determinar el ajuste a la normalidad de cada variable; cuando los valores se ajustaban a una distribución normal se utilizó la t de Student, en el caso contrario se ha utilizado la prueba no paramétrica de Mann-Whitney. Todos los contrastes fueron de dos colas y se ha considerado como estadísticamente significativo un valor de $\mathrm{p}<0,05$. Las variables significativas en el análisis bivariante se han introducido en un modelo de regresión logística múltiple de exclusión escalonada paso a paso, utilizando la mortalidad como variable dependiente. Para su inclusión en el modelo de regresión, se ha procedido a la dicotomización de las variables continuas; para seleccionar el valor de corte, se han dividido los valores de las variables en cuartiles y determinado el porcentaje de pacientes con bacteriemia de cada cuartil. Si existía un cuartil en el que se observaba una modificación en la probabilidad, se utilizó como valor de corte, en los cuartiles centrales el valor medio y en los cuartiles superior e inferior el límite inferior y superior del cuartil respectivamente (14). Si no había ningún cuartil con variación evidente de la probabilidad de la variable dependiente, se utilizó el valor de la mediana. Las variables que a priori no mostraban un interés clínico evidente y que se utilizaban para el cálculo de otras, no fueron incluidas en el análisis multivariante (por ejemplo, la frecuencia respiratoria y la puntuación en la escala de coma de Glasgow se utilizan para el cálculo del APACHE II). Los datos se han analizado con el paquete estadístico SPSS 11.0 para ordenadores del entorno Macintosh. 


\section{RESULTADOS}

Se han observado 115 casos de bacteriemia en 114 pacientes. La incidencia de bacteriemia fue del 56,6 por 1.000 ingresos hospitalarios. Las principales características epidemiológicas y clínicas de la serie y los factores de riesgo para la adquisición de bacteriemia se recogen en la tabla I. El $56,5 \%$ de los pacientes $(n=65)$ eran mujeres y el $43,5 \%(\mathrm{n}=50)$ hombres. La media de edad ( \pm desviación estándar) fue de 74,1 \pm 15,4 años (rango 19-104 años; mediana 76 años). Se detectó algún factor de riesgo para el desarrollo de bacteriemia en 65 casos $(56,5 \%)$; destacan la alta prevalencia de diabetes mellitus $(25,2 \%)$ entre los factores intrínsecos y el sondaje uretral $(12,2 \%)$ entre los extrínsecos. Los focos de bacteriemia y los diagnósticos clínicos se recogen en la tabla II. El foco urinario supuso el $57,4 \%$ de los casos.

Los aislamientos microbiológicos obtenidos en los hemocultivos se recogen en la tabla III; destaca el predominio de los bacilos aerobios gram negativos con 88 casos $(70,4 \%$ de los aislamientos) sobre los gram positivos con $22(17,6 \%)$. Los microorganismos anaerobios constituyeron el $4 \%$ de los aislamientos. El microorganismo aislado con mayor frecuencia fue Escherichia coli (54,4\% de los aislamientos), lo que refleja el predominio del foco urinario; Streptococcus pneumoniae, con un $6,4 \%$ de los aislamientos, ocupa la segunda posición en orden de frecuencia. Las bacteriemias polimicrobianas supusieron un $7 \%$ de los casos.

\section{TABLA I}

CARACTERÍSTICAS EPIDEMIOLÓGICAS Y CLÍNICAS DE LOS PACIENTES CON BACTERIEMIA $(n=115)$

\begin{tabular}{lc}
\hline Edad (años) & $74,1 \pm 15,4$ \\
Sexo & \\
Mujeres & $65(56,5)$ \\
Varones & $50(43,5)$ \\
Enfermedad de base & $50(43,5)$ \\
No fatal & $62(53,9)$ \\
Últimamente fatal & $3(2,6)$ \\
Rápidamente fatal & $2,26 \pm 1,92$ \\
Índice de comorbilidad & $4,2 \pm 5,2$ \\
Estado funcional & $14,1 \pm 7,3$ \\
APACHE II & \\
Factores de riesgo & \\
Intrínsecos & $29(25,2)$ \\
Diabetes & $19(16,5)$ \\
Neoplasia & $9(7,8)$ \\
Insuficiencia renal crónica & $2(1,7)$ \\
Hepatopatía crónica & \\
Extrínsecos & \\
Sondaje uretral & $14(12,2)$ \\
Tratamiento inmunosupresor & $8(7)$ \\
Acceso venoso & $5(4,3)$ \\
Mortalidad (a los 28 días) (*) & $17(15,3)$ \\
\hline
\end{tabular}

Las variables cuantitativas se expresan con la media \pm desviación estándar; las variables cualitativas con su valor absoluto y porcentaje (entre paréntesis). APACHE II: Acute Physiology and Chronic Health Evaluation II. (*) El cálculo se realiza sobre los 111 episodios en los que se conoce la evolución a los 28 días.

\begin{tabular}{lc}
\multicolumn{2}{c}{ TABLA II } \\
\multicolumn{2}{c}{ FOCOS Y DIAGNÓSTICOS CLÍNICOS FINALES DE LOS } \\
\hline \multicolumn{2}{c}{$n(\%)$} \\
\hline Foco de bacteriemia & $66(57,4)$ \\
\hline Foco urinario & 36 \\
Pielonefritis aguda & 30 \\
Infección urinaria & $9(7,8)$ \\
Foco respiratorio & 9 \\
Neumonía & $12(10,4)$ \\
Sin foco aparente & 8 \\
Bacteriemia primaria & 4 \\
Otros & $15(13)$ \\
Foco abdominal & 4 \\
Gastroenteritis aguda & 3 \\
Colangitis & 2 \\
Diverticulitis & 6 \\
Otros & $8(7)$ \\
Foco cutáneo & 5 \\
Celulitis & 3 \\
Úlcera de decúbito infectada & 2 \\
Foco vascular & $5(4,4)$ \\
Endocarditis & 3 \\
Otras & 2 \\
Total & $11500)$ \\
\hline
\end{tabular}

TABLA III

AISLAMIENTOS MICROBIOLÓGICOS EN PACIENTES CON BACTERIEMIA

\begin{tabular}{lc}
\hline Microorganismo & $n(\%)$ \\
\hline Bacilos gram negativos & $88(70,4)$ \\
E. coli & $68(54,4)$ \\
Klebsiella spp. & $4(3,2)$ \\
Proteus spp. & $6(4,8)$ \\
Salmonella spp. & $5(4)$ \\
Otros Gram negativos & $5(4)$ \\
Cocos Gram positivos & $22(17,6)$ \\
Staphylococcus aureus & $6(4,8)$ \\
Streptococcus spp. & $4(3,2)$ \\
Streptococcus pneumoniae & $8(6,4)$ \\
Staphylococcus coagulasa negativos & $4(3,2)$ \\
Enterococcus spp. & $6(4,8)$ \\
Anaerobios & $5(4)$ \\
Neisseria meningitidis & $2(1,6)$ \\
Otros microorganismos & $2(1,6)$ \\
Bacteriemias polimicrobianas & $8(7)$ \\
Total & $125(100)$
\end{tabular}

Se recuperaron 125 microorganismos en 115 episodios de bacteriemia. En 6 casos se aislaron 2 microorganismos, mientras que en 2 casos se aislaron 3. 
La mortalidad a los 28 días fue del $15,3 \%$ (17 de 111 pacientes); en 4 casos fue imposible determinar su situación. En las tablas IV, V y VI se recogen los resultados del análisis bivariante. En la tabla VII se reflejan las variables asociadas

\begin{tabular}{lcccc}
\multicolumn{5}{c}{ TABLA IV } \\
\multicolumn{5}{c}{$\begin{array}{c}\text { PRONÓSTICO DE BACTERIEMIA. ANÁLISIS BIVARIANTE. } \\
\text { VARIABLES CUANTITATIVAS CLÍNICAS }\end{array}$} \\
\hline Variable & $n$ & Vivos & Fallecidos & $p$ \\
\hline Edad (años) & 111 & $72,1 \pm 15,7$ & $82,5 \pm 11,5$ & $<0,05$ \\
IC & 111 & $2,2 \pm 1,8$ & $3,1 \pm 2,3$ & NS \\
Temperatura ( $\left.{ }^{\circ} \mathrm{C}\right)$ & 111 & $38,6 \pm 0,6$ & $38,3 \pm 0,5$ & $<0,05$ \\
FC (Ipm) & 111 & $104 \pm 19$ & $107 \pm 21$ & NS \\
FR (rpm) & 111 & $20 \pm 6$ & $26 \pm 6$ & $<0,001$ \\
TAM (mm Hg) & 111 & $89 \pm 17$ & $78 \pm 28$ & NS \\
ECG & 111 & $14 \pm 1,5$ & $11 \pm 3,7$ & $<0,001$ \\
APACHE II & 111 & $12,6 \pm 6$ & $22,9 \pm 8,8$ & $<0,001$ \\
SOFA & 111 & $2,4 \pm 2,2$ & $5,5 \pm 2,9$ & $<0,001$ \\
\hline
\end{tabular}

$\mathrm{N}$ : número de pacientes en los que se dispone de cada resultado. p: valor de la " $\mathrm{p}$ " en las pruebas estadísticas utilizadas (t de Student o $U$ de Mann-Whitney). IC: índice de comorbilidad de Charlson. FC: frecuencia cardiaca. Lpm: latidos por minuto. FR: frecuencia respiratoria. Rpm: respiraciones por minuto. TAM: presión arterial media. ECG: puntuación en la escala de coma de Glasgow. APACHE II: Acute Physiology and Chronic Health Evaluation II. SOFA: Sepsis-related Organ Failure Assessment.

\section{TABLA V}

PRONÓSTICO DE BACTERIEMIA. ANÁLISIS BIVARIANTE. VARIABLES CUANTITATIVAS DE LABORATORIO

\begin{tabular}{|c|c|c|c|c|}
\hline Variable & $n$ & Vivos & Fallecidos & $p$ \\
\hline Leucocitos $\left(\times 10^{3} / \mathrm{mm}^{3}\right)$ & 111 & $13 \pm 5,8$ & $18,7 \pm 16,8$ & NS \\
\hline PMN (\%) & 111 & $84,8 \pm 9,8$ & $81,9 \pm 19,8$ & NS \\
\hline Hemoglobina (g/dL) & 111 & $12,7 \pm 2,1$ & $11,4 \pm 2,2$ & $<0,05$ \\
\hline VSG (mm) & 108 & $70 \pm 26$ & $75 \pm 31$ & NS \\
\hline Plaquetas $\left(\times 10^{3} / \mathrm{mm}^{3}\right)$ & 111 & $194 \pm 85$ & $246 \pm 159$ & NS \\
\hline Glucosa (mg/dL) & 111 & $170 \pm 94$ & $174 \pm 108$ & NS \\
\hline Urea (mg/dL) & 111 & $63,1 \pm 41,9$ & 96,2 & NS \\
\hline Creatinina (mg/dL) & 111 & $1,36 \pm 1,08$ & $1,48 \pm 0,82$ & NS \\
\hline Sodio (mEq/L) & 111 & & & NS \\
\hline Potasio (mEq/L) & 110 & $4,1 \pm 0,6$ & $4.3 \pm 0,8$ & NS \\
\hline GPT (U/L) & 110 & $62 \pm 20$ & $28 \pm 34$ & NS \\
\hline Bilirrubina (mg/dL) & 108 & $0,96 \pm 0,67$ & $1,38 \pm 1,64$ & NS \\
\hline Fosfatasa alcalina (U/L) & 101 & $198 \pm 101$ & $338 \pm 195$ & $<0,05$ \\
\hline CK (U/L) & 95 & $3.297 \pm 27.531$ & $389 \pm 457$ & $<0,01$ \\
\hline LDH (U/L) & 111 & $563 \pm 875$ & $582 \pm 157$ & $<0,01$ \\
\hline PCR (mg/dL) & 102 & $14,1 \pm 9$ & $16,2 \pm 5,7$ & NS \\
\hline Albúmina (g/dL) & 108 & $3 \pm 0,5$ & $2,7 \pm 0,6$ & $<0,05$ \\
\hline Bicarbonato (mmol/L) & 59 & $22,3 \pm 4$ & $23,7 \pm 5,8$ & NS \\
\hline $\mathrm{pH}$ & 59 & $7,4 \pm 0,06$ & $7,42 \pm 0,08$ & NS \\
\hline
\end{tabular}

$\mathrm{N}$ : número de pacientes en los que se dispone de cada resultado. $\mathrm{p}$ : valor de la " $\mathrm{p}$ " en las pruebas estadísticas utilizadas ( $t$ de Student o $U$ de Mann-Whitney). PMN: polimorfonucleares. VSG: velocidad de sedimentación globular. PCR: proteína $C$ reactiva.

\begin{tabular}{|c|c|c|c|c|}
\hline \multicolumn{5}{|c|}{ TABLA VI } \\
\hline \multicolumn{5}{|c|}{$\begin{array}{c}\text { PRONÓSTICO DE BACTERIEMIA. ANÁLISIS BIVARIANTE. } \\
\text { VARIABLES CUALITATIVAS }\end{array}$} \\
\hline Variable & $\begin{array}{l}\text { Total } \\
(\%)\end{array}$ & $\begin{array}{l}\text { Vivos } \\
(\%)\end{array}$ & $\begin{array}{l}\text { Fallecidos } \\
\text { (\%) }\end{array}$ & $p$ \\
\hline Sexo femenino & 55 & 52,1 & 70,6 & NS \\
\hline Enfermedad de base UF/RF & 57,7 & 51,1 & 94,1 & $<0,01$ \\
\hline Estado funcional dependiente & 30,6 & 22,3 & 76,5 & $<0,001$ \\
\hline Antibiótico previo & 9,9 & 10,6 & 5,9 & NS \\
\hline Diabetes & 25,2 & 24,5 & 29,4 & NS \\
\hline Insuficiencia renal crónica & 8,1 & 7,5 & 11,8 & NS \\
\hline Demencia & 36 & 29,8 & 70,6 & $<0,01$ \\
\hline Neoplasia & 16,2 & 14,9 & 23,5 & NS \\
\hline Hepatopatía crónica & 1,8 & 1,1 & 5,9 & NS \\
\hline Shock séptico & 10 & 4,3 & 41,2 & $<0,001$ \\
\hline Tratamiento inicial inadecuado & 17,1 & 13,8 & 35,3 & $<0,05$ \\
\hline Foco urinario & 57,7 & 61,7 & 35,3 & $<0,05$ \\
\hline
\end{tabular}

UF: últimamente fatal. RF: rápidamente fatal (McCabe y Jackson). $p$ : valor de la " $\mathrm{p}$ " en las pruebas estadísticas utilizadas (Chi-cuadrado y test exacto de Fischer). Estado funcional dependiente: puntuación $\geq 8$ en la escala de Plutchik.

\section{TABLA VII}

PRONÓSTICO DE BACTERIEMIA. ANÁLISIS MULTIVARIANTE

\begin{tabular}{lccccc}
\hline Variable & $B$ & $E S$ & OR & OR IC 95\% & $p$ \\
\hline Shock séptico & 2,34 & 1,04 & 10,4 & $3,7-29,4$ & $<0,05$ \\
Foco no urinario & 2,23 & 0,93 & 9,3 & $3,7-23,6$ & $<0,05$ \\
APACHE II $\geq 20$ & 1,71 & 0,78 & 5,5 & $2,5-12,1$ & $<0,05$ \\
Estado funcional $\left({ }^{*}\right)$ & 1,57 & 0,82 & 4,8 & $2,1-10,9$ & 0,056 \\
Constante & $-4,84$ & 1,02 & & &
\end{tabular}

B: coeficiente. ES: error estándar del coeficiente. OR: odds ratio. IC 95\%: intervalos de confianza al 95\%. APACHE II: Acute Physiology and Chronic Health Evaluation II. (*) estado funcional dependiente, definido con una puntuación en la escala de Plutchik $\geq 8$.

de forma independiente con la mortalidad a los 28 días en la regresión logística. La mortalidad se asoció al diagnóstico de shock séptico, el foco de bacteriemia diferente del urinario, la puntuación en el APACHE II mayor o igual de 20 y la existencia de un estado funcional dependiente previo al episodio de bacteriemia.

\section{DISCUSIÓN}

La mortalidad cruda a los 28 días de la bacteriemia en nuestros pacientes fue del $15,3 \%$, cifra que se sitúa dentro del rango de lo publicado con anterioridad. En la literatura, la mortalidad de la bacteriemia considerada globalmente fue por término medio de $21,3 \%$, con un rango entre $14 \%$ y $29,2 \%$ $(1,6,15-18)$. En las series que incluyen únicamente bacterie- 
mias adquiridas en la comunidad la mortalidad media fue de $19,5 \%$ (rango 14-29,2\%) (19,20), mientras que en las que incluían bacteriemias nosocomiales fue del 31\% (rango 21$38 \%$ ) (21-23). En dos estudios que recogían exclusivamente las bacteriemias diagnosticadas en servicios de Medicina Interna (tanto extrahospitalarias como nosocomiales), la mortalidad estuvo en torno al $13,5 \%(24,25)$.

Los trabajos publicados que estudian los factores pronósticos de la bacteriemia son muy numerosos. Las variables que se han investigado son muy heterogéneas; su elección y definición son diferentes según el marco en el que se realiza el estudio y el criterio de los autores. Desde un punto de vista didáctico, las variables incluidas en los modelos de predicción de mortalidad de la bacteriemia pueden agruparse en: a) variables dependientes del paciente (edad, sexo, enfermedades de base y situación funcional); b) variables dependientes de la propia infección (presentación clínica, gravedad, complicaciones, etc.); c) variables relacionadas con los microorganismos implicados; y d) variables dependientes del tratamiento. Los factores pronósticos que se repiten con mayor frecuencia en la literatura son la existencia de shock séptico, la edad, la existencia de patología de base y el tratamiento antibiótico empírico inadecuado.

El shock séptico aparece en la mayor parte de los estudios, como la variable más importante en la predicción del pronóstico de la bacteriemia, tanto en series generales $(15-18,26)$, como en series de ancianos (27), pacientes infectados por el VIH (28), oncológicos (29) o ingresados en UCI $(23,30)$, así como en bacteriemias de adquisición nosocomial (22), extrahospitalarias (19) o por bacilos gram negativos (31). Además, el shock séptico es el factor con una mayor asociación a la mortalidad en la mayor parte de las series en que aparece en el análisis multivariante $(16,17,22,23,27,29,32,33)$, como sucede en nuestro trabajo.

La relación entre la edad y el riesgo de muerte en la bacteriemia ha sido puesta de manifiesto en múltiples estudios (15,17,18,34-37). Las razones que ensombrecen el pronóstico de la bacteriemia en el anciano no son bien conocidas; las circunstancias que podrían desempeñar algún papel son la mayor incidencia de enfermedades crónicas o debilitantes, la propia senescencia del sistema inmune o el retraso diagnóstico y terapéutico, asociado a las presentaciones clínicas atípicas (27). En nuestra serie, la edad es significativamente superior en los fallecidos en al análisis bivariante; sin embargo, pierde la significación al efectuar la regresión logística.

La existencia de enfermedades crónicas previas al episodio de bacteriemia también constituye en otras series un factor de mal pronóstico. En varios estudios la clasificación de las enfermedades de base de McCabe y Jackson (8) ha mostrado su utilidad en la predicción de la mortalidad $(26,31,34,35)$. Por otra parte, en un estudio se ha observado que el estado funcional previo a la bacteriemia, medido por la escala de Barthel, es un importante factor de riesgo de mortalidad (16). En nuestro trabajo, una situación de dependencia, definida con una puntuación $\geq 8$ en la escala de
Plutchik (9) se asoció de forma independiente con la mortalidad. Estos resultados sugieren que la edad y la patología de base pueden no tener, por sí mismos, tanta trascendencia pronóstica en la bacteriemia, sino que ésta deriva del trastorno de la capacidad funcional que condicionan.

Las escalas que determinan la gravedad y la probabilidad de muerte individual de los pacientes, también han mostrado su utilidad en la bacteriemia $(32,35)$. Las más utilizadas han sido el Acute Physiology and Chronic Health Evaluation (APACHE II y III) (11,38), el Simplified Acute Physiology Score (SAPS) (39), el Multiple Organ Dysfunction Score (MODS) (40) y el Sepsis-related Organ Failure Assesssment (SOFA) (12). A pesar de que estas escalas se han aplicado generalmente en la UCI, nuestro trabajo muestra su utilidad en otras áreas del hospital.

Otro factor de mal pronóstico identificado en nuestro estudio fue el foco de la bacteriemia diferente del urinario. Este hecho ha sido observado en trabajos previos sobre series generales de bacteriemia (34) y sobre bacteriemia por bacilos gram negativos (37). En otros estudios se ha concluido que, tanto el foco respiratorio $(15,17,19,28)$, como el abdominal $(15,19,30)$, el desconocido $(15,27)$ y la coexistencia de varios focos se asocian a un exceso de mortalidad (19). Por el contrario los focos urinario $(34,37)$ y asociado a catéter $(26)$ tienen globalmente un pronóstico mejor.

En muchos estudios sobre el pronóstico de las bacteriemias, se ha observado que el tratamiento inadecuado se asocia de forma independiente con la mortalidad, tanto en series que estudian de forma global la bacteriemia $(15,17,18,26,32,33)$, como en series limitadas a ancianos $(27,41)$, infectados por el VIH (28) o a ingresados en UCI (42), así como en bacteriemias de origen urinario (43) o respiratorio (36) y por bacilos gram negativos $(31,37)$. La elección de un tratamiento antibiótico inadecuado puede afectar a un porcentaje de pacientes entre un $10 \%$ y un $35 \%(15,17,32,36,44)$. En nuestra serie, el tratamiento antibiótico inicial incorrecto fue significativamente más frecuente en los enfermos que fallecieron; sin embargo, al realizar la regresión logística esta variable no quedó incluida en el modelo.

Otros factores de mal pronóstico identificados en la literatura son la adquisición nosocomial de la bacteriemia $(16,18)$, variables de laboratorio (urea, albúmina, bilirrubina, hemoglobina y recuento leucocitario) $(15,28,29,43)$ e identidad del microorganismo implicado (Pseudomonas spp, Klebsiella spp, Clostridium spp, S. aureus, hongos y bacteriemias polimicrobianas) $(15,29,36,37)$.

En resumen, la bacteriemia adquirida en la comunidad supone un problema clínico frecuente en los servicios de Medicina Interna, que conlleva una mortalidad cruda asociada próxima al $15 \%$. Los factores de riesgo de mortalidad identificados en nuestra serie, se relacionan con la gravedad de la infección (shock séptico y puntuación en el APACHE II) y su foco inicial (mejor pronóstico para el foco urinario) y con la situación funcional previa del paciente. La edad avanzada y el tratamiento antimicrobiano empírico inicial adecuado no constituyeron factores independientes de mortalidad. 


\section{Bibliografía}

1. Matas L, Martí C, Morera A, Sierra M, Vilamala A, Corcoy F y Grupo de Microbiólogos de Hospitales Comarcales de Barcelona. Bacteriemia en 13 hospitales generales de la provincia de Barcelona. Estudio prospectivo de 1.674 episodios. Enf Infec Microbiol Clin 1995; 13: 345-55.

2. Simonsen L, Conn LA, Pinner RW, Teutsch S. Trends in infectious discase hospitalizations in the United States, 1980-1994. Arch Intem Med 1998; 158: 1923-8.

3. McBean M, Rajamani S. Increasing rate of hospitalization due to septicemia in the US elderly population, 1986-1997. J Infect Dis 2001; 183: 596603

4. Centers for Disease Control. National Center for Health Statistics. Mortality patterns-United States, 1990. Monthly Vital Statistics Report 1993; 41: 5 .

5. Fariñas MC, Fariñas Alvarez C, García Palomo JD, González Macías J. Bacteriemia y sepsis. Aspectos etiológicos y patogénicos. Clínica y diagnóstico. Medicine (Madrid) 1998; 7: 3377-83.

6. Sota Busselo M, Ezpeleta Baquedano C, Cisterna Cáncer R. Bacteriemia: estudio multicéntrico español con 5.000 casos. Rev Clin Esp 1997; 197 (Sup 5): 3-9.

7. Charlson ME, Pompei P, Ales KL, Mackenzie CR. A new method of classifying prognostic comorbidity in longitudinal studies: development and validation. J Chron Dis 1987; 40: 373-83.

8. McCabe WR, Jackson GG. Gram-negative bacteriemia. Etiology and ecology. Arch lntern Med 1962; 110: 845-55.

9. Perlado F, Alastuey C, Espinosa C, Clerencia M, Ochoa P, Domingo D Valoración del estado funcional en ancianos hospitalizados: la escala Plutchik. Med Clin (Barc) 1996; 107: 45-9.

10. Teasdale G, Jennet B. Assesement of coma and impaired consciousness: a practical scale. Lancet 1974; 872: 81-4.

11. Knaus WA, Draper EA, Wagner DP, Zimmerman JE. APACHE II: a severity of disease classification system. Crit Care Med 1985; 13: 818-29.

12. Vicent JL, Moreno R, Takala J, et al. The SOFA (Sepsis-related Organ Failure Assessment) score to describe organ dysfunction/failure. Intensive Care Med 1996; 22: 707-10.

13. Lizarralde E. Bacteriemia adquirida en la comunidad en pacientes ingresados en un servicio de Medicina Interna. Estudio descriptivo, análisis de los factores pronósticos y elaboración de un modelo de predicción clínica (tesis doctoral). Bilbao: Universidad del País Vasco. 2002.

14. Chin DP, Reingold AL, Horsburgh CR, Yajko DM, Hadley WK, Elkin EP, et al. Predicting Mycobacterium avium complex bacteremia in patients infected with human immunodeficiency virus: a prospectively validated model. Clin Infect Dis 1994; 19: 668-74.

15. Weinstein MP, Towns ML, Quartey SM, Mirrett S, Reimer LG, Parmigiani $\mathrm{G}$, et al. The clinical significance of positive blood cultures in the 1990s: a prospective comprehensive evaluation of the microbiology, epidemiology, and outcome of bacteremia and fungemia in adults. Clin Infect Dis 1997; 24: 584-602.

16. Deulofeu F, Cervelló B, Capell S, Martí C, Mercadé V. Predictors of mortality in patients with bacteremia: the importance of functional status. $\mathrm{J}$ Am Geriatr Soc 1998; 46: 14-8.

17. Rojo MD, Pinedo A, Clavijo E, García-Rodríguez A, García MV. Factores que influyen en la evolución de la bacteriemia. Estudio prospectivo en un hospital universitario. Enf Infec Microbiol Clin 1999; 17: 439-44.

18. Noguerado Asensio A, Ruiz Giardin JM, Pizarro Portillo A, Méndez García J, La Hulla Pastor F, Fernández Escribano M, et al. Análisis de factores pronósticos de mortalidad de las bacteriemias y fungemias en un Hospital Universitario. Evolución en 10 años. Rev Clin Esp 2001; 201: 122-9.

19. Lark RL, Saint S, Chenoweth C, Zemencuk JK, Lipsky BA, Plorde JJ. Four-year prospective evaluation of community-acquired bacteremia: epidemiology, microbiology, and patient otucome. Diagn Microbiol Infect Dis 2001; 41: 15-22.

20. Mylotte JM, Kahler L, McCann C. Community-acquired bacteremia at a teaching versus a nonteaching hospital: impact of acute severity of illness on 30-day mortality. Am J Infect Control 2001; 29: 13-9.

21. Ezpeleta Baquedano C. Bacteriemias intrahospitalarias. Rev Clin Esp 1997; 197 (Sup 5): 15-20.

22. Lark RL, Chenoweth C, Saint S, Zemencuk JK, Lipsky BA, Plorde JJ. Four year prospective evaluation of nosocomial bacteremia: epidemiology, microbiology, and patient outcome. Diagn Microbiol Infect Dis 2000; 38: 131-40.

23. Edgeworth JD, Treacher DF, Eykyn SJ. A 25-year study of nosocomial bacteremia in an adult intensive care unit. Crit Care Med 1999; 27: 1648-50.
24. Gómez J, Moldenhauer F, Martínez Ros C, Ruiz Gómez J, Martínez Hernández J, Canteras $\mathrm{M}$ et al. Epidemiología y factores pronósticos de las bacteriemias en un departamento de Medicina Interna. Estudio prospectivo durante 1987. Rev Esp Microbiol Clin 1990; 5: 39-44.

25. Lizarralde E, Gutiérrez Macías A, Martínez Odriozola P, Teira Cobo R, Santamaría Jaúregui, Miguel De la Villa F. Estudio prospectivo de bacteriemia en un servicio de Medicina Interna. Gac Med Bilbao 1999; 96: 35 39.

26. Bates DW, Pruess KE, Lee TH. How bad are bacteremia and sepsis? Outcomes in a cohort with suspected bacteremia. Arch Intern Med 1995; 155 $593-8$

27. Corredoira Sánchez JC, Casariego Vales E, Alonso García P, Amparo Coira Nieto, Varela Otero J, López Alvarez MJ, et al. Bacteriernia en ancianos. Aspectos clínicos y factores pronósticos. Med Clin (Barc) 1997 109: $165-70$.

28. Omeñaca C, Turett G, Yarrish R, Astiz M, Lin R, Kislak JW, et al. Bacteremia in HIV-infected patients: short term predictors of mortality. J Acquir Immune Defic Syndr 1999; 22: 155-60.

29. Elting LS, Rubenstein EB, Rolston KVI, Bodey GP. Outcomes of bacteremia in patients with cander and neutropenia: observations from two decades of epidemiological and clinical trials. Clin Infect Dis 1997; 25: 247-59.

30. Vallés J, León C, Alvarez-Lerma F, for The Spanish Collaborative Group for Infections in Intensive Care Units. Nosocomial bacteremia in critically ill patients: a multicenter study evaluating epidemiology and prognosis. Clin Infect Dis 1997; 24: 387-95.

31. Uzun O, Akalin HE, Hayran M, Unal S. Factors influencing prognosis in bacteremia due to gram-negative organisms: evaluation of 448 episodes in a Turkish university hospital. Clin Infect Dis 1992; 15: 866-73.

32. Byl B, Clevenbergh P, Jacobs F, Struelens MJ, Zech F, Kentos A, Thys JP. Impact of infectious diseases specialists and microbiological data on the appropriateness of antimicrobial therapy for bacteremia. Clin Infect Dis 1999; 29: 60-6.

33. Pazos Añón R, Fernández Rodríguez R, Paz Vidal I, Tinajas A, Cantón I, Abel $\mathrm{V}$ et al. Factores pronósticos de la bacteriemia: estudio prospectivo. An Med Intern (Madrid) 2001; 18: 415-20.

34. Brun-Buisson C, Doyon F, Carlet $\mathrm{J}$ and the French Bacteremia-Sepsis Study Group. Bacteremia and severe sepsis in adults: A multicenter prospective survey in ICUs and wards of 24 hospitals. Am J Respir Crit Care Med 1996; 154: 617-24.

35. Renaud B, Brun-Buisson C, and the Bacteremia Study Group. Outcomes of primary and catheter-related bacteremia. A cohort and case-control study in critically ill patients. Am J Respir Crit Care Med 2001; 163: 1584-90.

36. Bishara J, Leibovici L, Ashkenazi S, Samra Z, Pitlik S. Seven-year study of bacteraemic pneumonia in a single institution. Eur J Clin Microbiol Infect Dis 2000; 19: 926-31.

37. Pedersen G, Schonheyder HC, Sorensen HT. Antibiotic therapy and outcome of monomicrobial gram negative bacteremia: a 3-year populationbased study. Scand J Infect Dis 1997; 29: 601-6.

38. Knaus WA, Wagner DP, Draper EA, Zimmerman JE, Bergner M, Bastos JE. The APACHE III prognostic system. Risk prediction of hospital mortality for critically ill hospitalized adults. Chest 1991; 100: $1619-36$

39. Le Gall JR, Lemeshow S, Saulnier F. A new simplified Acute Physiology Score (SAPS II) based on a European/North American multicenter study. JAMA 1993; 270: 2957-63

40. Marshall JC, Cook DJ, Christou NV, Bernard GR, Sprung CL, Sibbald WJ. Multiple organ dysfunction score: a reliable descriptor of a complex clinical outcome. Crit Care Med 1995; 23: 1638-52.

41. Rubio Félix S, Aznar Muñoz R, Martín Algora I, Egido Murciano M, Ferrero Cáncer M, Mairal Claver P et al. Bacteriemia en el anciano: factores asociados y pronósticos. Rev Clin Esp 1998; 198: 7-10.

42. Ibrahim EH, Sherman G, Ward S, Fraser VJ, Kollef MH. The influence of inadequate antimicrobial treatment of bloodstream infections on patient outcomes in the ICU setting. Chest 2000; 118: 146-55.

43. Bishara J, Leibovici L, Huminer D, Drucker M, Samra Z, Konisberger H, et al. Five-year prospective study of bacteraemic urinary tract infection in a single institution. Eur J Clin Microbiol Infect Dis 1997; 16: 563-7.

44. Gross PA, Barrett TL, Dellinger EP, Krause PJ, Martone WJ, McGowan JE, et al. Quality standard for the treatment of bacteremia. Clin Infect Dis 1994; 18: 428-30. 